\title{
Correction to: Systematic review and metal analysis on three important fungal group (dermatophytes, yeasts and saprophytes) isolated from Iranian swimming pools
}

\author{
Pouran Makhdoumi ${ }^{1} \cdot$ Parya Akbari $^{1} \cdot$ Nezam Mirzaei $^{2} \cdot$ Hooshyar Hossini $^{3}$ (D) $\cdot$ Edris Hoseinzadeh $^{4}$ \\ Published online: 7 June 2021 \\ (C) Springer Nature Switzerland AG 2021
}

\section{Correction to: Journal of Environmental Health Science and Engineering} https://doi.org/10.1007/s40201-021-00670-5

The word 'tree' in title is replaced with 'three'. The original article has been corrected.

Publisher's note Springer Nature remains neutral with regard to jurisdictional claims in published maps and institutional affiliations.

The online version of the original article can be found at https://doi.org/ 10.1007/s40201-021-00670-5

Nezam Mirzaei

nezammirzaei@yahoo.com

$\triangle$ Hooshyar Hossini

hoo.hosseini@gmail.com

1 Students Research Committee, Kermanshah University of Medical Sciences, Kermanshah, Iran

2 Department of Environmental Health Engineering, Social Determinants of Health (SDH) Research Center, Kashan University of Medical Sciences, Kashan, Iran

3 Department of Environmental Health Engineering, Faculty of Health, Kermanshah University of Medical Sciences, Kermanshah, Iran

4 Student Research Committee, Saveh University of Medical Sciences, Saveh, Iran 